Original Article

\title{
Comparison of lumbar spinal angle between normal body mass index and overweight young adults
}

\author{
Soontharee Taweetanalarp, PhD ${ }^{1)^{*}}$, Nithima Purepong, $\mathrm{PhD}^{1)}$ \\ 1) Department of Physical Therapy, Faculty of Allied Health Sciences, Chulalongkorn University: \\ 154 Rama 1 Rd., Patumwan, Bangkok 10330, Thailand
}

\begin{abstract}
Purpose] This study compared the upper and lower lumbar angles of normal body mass index and overweight young adults, and examined the relationships among body mass index, waist circumferences, and lumbar angles. [Subjects and Methods] Sixty participants aged 18-25 years were recruited and allocated to 2 groups ( $\mathrm{n}=30$ per group): normal body mass index $\left(18.5-24.9 \mathrm{~kg} / \mathrm{m}^{2}\right.$ ) and overweight group (body mass index, $\geq 25.0 \mathrm{~kg} /$ $\mathrm{m}^{2}$ ). During lumbar angle measurement, the participants stood in a relaxed position with bare feet. The upper and lower lumbar angles of each participant were measured using a flexible ruler, and the angle calculated by the tangent method. The waist circumference was also measured. [Results] The mean lower lumbar angle in the overweight group was significantly greater than that of the normal body weight group. Moreover, only the lower lumbar angle was associated with a significant increase in the body mass index $(\mathrm{r}=0.28)$. Waist circumference showed no association with the lumbar angles. [Conclusion] This is the first study to suggest that increased body weight could cause lower lumbar angle deviation in young adults. Further studies should investigate individuals with symptomatic back pain or back dysfunction and the impact of body weight on lumbar spinal angles.

Key words: Upper lumbar angle, Lower lumbar angle, Overweight
\end{abstract}

(This article was submitted Mar. 13, 2015, and was accepted Apr. 16, 2015)

\section{INTRODUCTION}

Spinal curvature in obese individuals might result from mechanical changes associated with obesity, such that the line of gravity and loading on the facet joints are altered ${ }^{1,2)}$. Excess body weight affects loading on the spine, which could result in angular changes in the vertebrae ${ }^{3)}$. The lumbar spine in obese individuals becomes hyperlordotic, a risk factor for low back pain and poor posture ${ }^{4-6)}$. Some researchers have reported that low back pain is associated with the increased body mass index $(\mathrm{BMI})^{7,8)}$.

With an increased lumbar lordosis, the biomechanics of the spine are altered by the increased loading on the facet joints and the increased shearing force of the lumbosacral junction, resulting in misalignment ${ }^{9-11)}$. Since the line of gravity usually passes in front of the second sacral vertebrae, the excess body weight will also generate a high compressive load on the spine and discs, which may increase the risk of nerve root compression, disc degeneration, injury to spinal ligaments, and derangements of the lumbosacral junction ${ }^{3,9,12-14)}$

An association between BMI and lumbar lordosis has been documented in several studies in which there was a sig-

\footnotetext{
*Corresponding author. Soontharee Taweetanalarp (E-mail: soontharee_ple@hotmail.com)
}

(C2015 The Society of Physical Therapy Science. Published by IPEC Inc. This is an open-access article distributed under the terms of the Creative Commons Attribution Non-Commercial No Derivatives (by-ncnd) License $<$ http://creativecommons.org/licenses/by-nc-nd/3.0/> . nificant correlation between BMI and lumbar lordosis ${ }^{15-17)}$. Additionally, the degree of lumbar lordosis showed a weak association with waist circumference but not waist-hip ratio ${ }^{18)}$. Most studies that have examined the lordosis angle in obesity have reported that BMI is associated with the lumbar lordosis $3,16,18-20)$. However, the upper and lower lumbar angles in individuals with excessive body weight have received limited attention. Although previous studies have investigated the lumbar angles in normal BMI individuals with and without low back pain ${ }^{21,22)}$, it is possible that, the upper and lower lumbar angles may differ between normal BMI and overweight individuals.

This study was intended to: 1) compare upper and lower lumbar angles between normal BMI and overweight young adults; 2) examine the relationships among BMI, waist circumference, and the lumbar angles. These findings can provide the preliminary data for developing a program intended to maintain the lumbar curve in overweight individuals.

\section{SUBJECTS AND METHODS}

\section{Subjects}

Sixty subjects aged 18-25 years old were recruited and divided into 2 groups ( $\mathrm{n}=30$ per group; male, 15; female, 15): normal BMI group (BMI, $18.5-24.9 \mathrm{~kg} / \mathrm{m}^{2}$ ) and overweight group $\left(\mathrm{BMI} \geq 25.0 \mathrm{~kg} / \mathrm{m}^{2}\right)^{23)}$. Exclusion criteria included a history of back pain or pain during testing, history of back surgery, leg length discrepancy of $\geq 1.5 \mathrm{~cm}$, and obvious scoliosis. Prior to participation, all subjects signed the informed consent. This study was approved by the Ethics Review Committee for Research Involving Human Research 
Table 1. Characteristics of participants

\begin{tabular}{lccccc}
\hline \multirow{2}{*}{ Groups } & \multicolumn{5}{c}{ mean \pm SD } \\
\cline { 2 - 6 } & $\begin{array}{c}\text { Age } \\
(\text { year })\end{array}$ & $\begin{array}{c}\text { Weight } \\
(\mathrm{kg})\end{array}$ & $\begin{array}{c}\text { Height } \\
(\mathrm{cm})\end{array}$ & $\begin{array}{c}\text { BMI } \\
\left(\mathrm{kg} / \mathrm{m}^{2}\right)\end{array}$ & $\begin{array}{c}\text { Waist circumference } \\
(\mathrm{cm})\end{array}$ \\
\hline Normal body mass index $(\mathrm{n}=30)$ & $20.4 \pm 1.3$ & $54.8 \pm 7.5$ & $165.6 \pm 7.7$ & $20.9 \pm 1.4$ & $69.5 \pm 7.0$ \\
Overweight $(\mathrm{n}=30)$ & $20.6 \pm 1.4$ & $80.8 \pm 14.3^{*}$ & $166.7 \pm 9.4$ & $28.9 \pm 3.5^{*}$ & $91.2 \pm 9.5^{*}$ \\
\hline
\end{tabular}

*Significant at $\mathrm{p}<0.05$

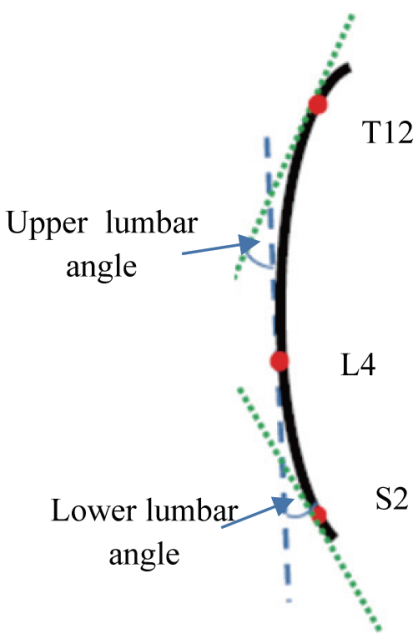

Fig. 1. Flexicurve traces at the levels of T12, L4, and S2 ${ }^{19}$ )

Subjects, Chulalongkorn University. Testing was conducted at the Faculty of Allied Health Sciences, Chulalongkorn University.

\section{Methods}

Subjects stood in a relaxed position with barefeet and their arms by their sides. All subjects had their weight, height, leg length, and waist circumference measured. Leg length was measured between the anterior superior iliac spine (ASIS) and the medial malleolus, using a measuring tape, with the subject in the supine position. Waist circumference was measured by taking the umbilicus as the reference point ${ }^{24)}$. For the lumbar angle, a tester palpated and marked on the skin over the spinous processes of $\mathrm{T} 12, \mathrm{~L} 4$, and $\mathrm{S} 2^{21}$. A flexible ruler was placed and applied over the lumbar curve and then it was removed to be traced on paper. Next, the tester drew 3 straight lines on each tangent at the marks corresponding to T12, L4, and S2. The upper and lower lumbar angles were measured separately by the tangent method $^{20,21)}$. The upper lumbar angle was derived from the intersection between the T12 and L4 lines whereas the lower lumbar angle was formed by the intersection between the L4 and S2 lines ${ }^{25}$ ) (Fig. 1). The subjects were tested in 3 trials, with one minute rests between trials, and the average value was used for further analysis. Before testing, the tester who took the measurements was examined for test-retest reliability; this was rated as high $(\mathrm{ICC}=0.9)$.

The data were analyzed using SPSS version 17 . The Kolmogorov-Smirnov test for normality was performed for all parameters. Descriptive statistics were calculated for age,
Table 2. Mean upper and lower lumbar angles

\begin{tabular}{lcc}
\hline \multirow{2}{*}{ Groups } & \multicolumn{2}{c}{ Lumbar angle $\left(\right.$ mean \pm SD) $\left({ }^{\circ}\right)$} \\
\cline { 2 - 3 } & Upper & Lower \\
\hline Normal body mass index & $14.5 \pm 5.9$ & $16.1 \pm 6.4$ \\
Overweight & $18.8 \pm 7.4$ & $22.9 \pm 7.9^{*}$ \\
\hline
\end{tabular}

*Significant at $\mathrm{p}<0.05$

Table 3. Correlation among lumbar angles, waist circumference, and BMI

\begin{tabular}{lcccc}
\hline \multirow{2}{*}{ Mean \pm SD } & \multicolumn{2}{c}{$\begin{array}{c}\text { Upper lumbar } \\
\text { angle }\end{array}$} & \multicolumn{2}{c}{$\begin{array}{c}\text { Lower lumbar } \\
\text { angle }\end{array}$} \\
\cline { 2 - 6 } & $\mathrm{r}$ & $\mathrm{p}$ & $\mathrm{r}$ & $\mathrm{p}$ \\
\hline Waist circumference & -0.01 & 0.93 & 0.12 & 0.36 \\
Body mass index & 0.05 & 0.69 & $0.28^{\#}$ & $0.03^{*}$ \\
\hline * Significant at $\mathrm{p}<0.05$ & & & & \\
\# Pearson correlation $(\mathrm{r})$ in range of & $0.10-0.29=$ & low correlation
\end{tabular}

weight, height, BMI, and waist circumference. All statistical analyses used a level of significance of $p<0.05$. Differences in the upper and lower lumbar angles between the 2 groups were analyzed using the independent t-test. Correlations between BMI and both lumbar angles, and between waist circumference and both lumbar angles, were calculated using Pearson's correlation.

\section{RESULTS}

Characteristics of both groups are shown in Table 1 . Significant differences between groups were found in weight, BMI, and waist circumference $(\mathrm{p}<0.05)$. However, there was no significant difference in age or height between groups ( $\mathrm{p}=0.633$ and $\mathrm{p}=0.616$, respectively).

The measurements of lumbar angles from the 2 groups are presented in Table 2. The means of both the upper and lower lumbar angles in the overweight group were greater than those in the normal BMI group. However, there was no significant difference in the upper lumbar angle between the 2 groups.

Significant differences of BMI between the 2 BMI groups were found only in the lower lumbar angle $(p=0.043)$. There was a weak correlation between BMI and the lower lumbar angle $(r=0.28, p=0.03)$; there was no correlations between any other paired comparison (Table 3 ). 


\section{DISCUSSION}

This study compared the upper and lower lumbar angles between normal and overweight individuals. The results indicated that there was an increase in the upper and lower lumbar angles in the overweight group, compared with the normal BMI group, particularly in terms of the lower lumbar angle. These results support the notion that excessive body weight contributes to an increased curvature of the lumbar spine.

Due to the lack of detailed descriptions regarding the lumbar angle of each intervertebral segment in the spine of an overweight individual, direct comparison of the results of this study with previous studies is difficult. In this study, both upper and lower lumbar angles in the overweight group were found to be higher than those in the normal BMI group. However, a statistically significant difference between the groups was demonstrated only in terms of the lower lumbar angle. An increase in the upper and lower lumbar angles in the overweight group is likely to occur more easily than in the normal BMI group. It appears that obesity induces an increase in the anterior pelvic tilt to compensate for the anterior shifting of the center of mass, resulting in increased flexion of the sacroiliac joints ${ }^{26)}$. Previous studies, which measured the lumbar curvature using different methods, have also reported that an increased BMI is associated with lumbar lordosis or angles ${ }^{1,2,5)}$. Consequently, it has been hypothesized that excess weight, can increase the lumbar angle both in the upper and lower lumbar spine.

Although this study investigated asymptomatic young adults, the significantly higher lower lumbar angle in the overweight subjects may place them at risk of low back pain. It was reported that increased BMI may cause low back pain due to restricted spine movement, followed by degenerative disc changes with compression effects and a change in the biomechanics of the spine ${ }^{6,27)}$. Additionally, a relationship between an increased lumbar lordosis with increased body weight has been found $\left.{ }^{7}, 15-17\right)$. The results of the present study demonstrated a significant correlation between the lower lumbar angle and BMI $(\mathrm{r}=0.28, \mathrm{p}=0.03)$. It is possible that overloading on the facet joints and intervertebral disc can affect the spinal curve. Any structural changes that may affect the integrity of the spinal tissues might be too minimal to have a high impact on the upper lumbar angle. This weak correlations is likely a result of the young age and the asymptomatic status of the subjects. Therefore, this study suggests that this is an early change, prior to the development of back pain and structural changes in young adulthood.

In our study, waist circumference did not correlate with the lumbar angles. However, Song et al. reported that the waist circumference in obese females (BMI $>30 \mathrm{~kg} / \mathrm{m}^{2}$ ) correlated with the lumbar lordosis ${ }^{18)}$. The study results may have been affected by the inclusion of obese subjects, rather than overweight subjects in our study. Therefore, the waist circumference may not be sufficiently large to establish any correlation. Further studies should consider the analysis of additional variables, such as waist-hip ratio, to distinguish the effects of overweight compared with obesity. The main limitation of this study was the lack of generalizability; all participants were students with sedentary lifestyles.
In conclusion, icreasing body weight could cause lower lumbar angle deviation in young adults. Therefore, young overweight individuals may be prone to developing low back pain in the future. There was a significant association between the lower lumbar angle and BMI. Waist circumference showed no association with the lumbar angles.

\section{REFERENCES}

1) Bener A, Alwash R, Gaber T, et al.: Obesity and low back pain. Coll Antropol, 2003, 27: 95-104. [Medline]

2) Lake JK, Power C, Cole TJ: Back pain and obesity in the 1958 British birth cohort. cause or effect? J Clin Epidemiol, 2000, 53: 245-250. [Medline] [CrossRef]

3) Youdas JW, Hollman JH, Krause DA: The effects of gender, age, and body mass index on standing lumbar curvature in persons without current low back pain. Physiother Theory Pract, 2006, 22: 229-237. [Medline] [CrossRef]

4) Polly DW Jr, Kilkelly FX, McHale KA, et al.: Measurement of lumbar lordosis. Evaluation of intraobserver, interobserver, and technique variability. Spine, 1996, 21: 1530-1535, discussion 1535-1536. [Medline] [CrossRef]

5) Leboeuf-Yde C: Body weight and low back pain. A systematic literature review of 56 journal articles reporting on 65 epidemiologic studies. Spine, 2000, 25: 226-237. [Medline] [CrossRef]

6) Caglayan M, Tacar O, Demirant A, et al.: Effects of lumbosacral angles on development of low back pain. J Musculoskeletal Pain, 2014, 22: 251-255. [CrossRef]

7) Youdas JW, Garrett TR, Egan KS, et al.: Lumbar lordosis and pelvic inclination in adults with chronic low back pain. Phys Ther, 2000, 80: 261-275. [Medline]

8) Park K, Seo K: The effects on the pain index and lumbar flexibility of obese patients with low back pain after PNF scapular and PNF pelvic patterns. J Phys Ther Sci, 2014, 26: 1571-1574. [Medline] [CrossRef]

9) Tsuji T, Matsuyama Y, Sato K, et al.: Epidemiology of low back pain in the elderly: correlation with lumbar lordosis. J Orthop Sci, 2001, 6: 307-311. [Medline] [CrossRef]

10) Ma SY, Gong WT, Ro HL: The correlation between lumbar lordosis, L4-5 disc angle, L4-5 disc height, and the lumbosacral angle in L4-5 HNP patients. J Phys Ther Sci, 2010, 22: 391-394. [CrossRef]

11) Cho M, Lee Y, Kim CS, et al.: Correlations among sacral angle, lumbar lordosis, lumbar ROM, static and dynamic lumbar stability in college students. J Phys Ther Sci, 2011, 23: 793-795. [CrossRef]

12) Bene E: [Measurement of the lumbosacral angle and its clinical significance]. Z Rheumatol, 1981, 40: 149-152. [Medline]

13) Maurata Y, Utsumi T, Hanaoka E, et al.: Change in lumbar lordosis in young patient with low back pain during a 10 years period. J Orthop Sci, 2006, 7: 618-622. [CrossRef]

14) McGill SM, Hughson RL, Parks K: Changes in lumbar lordosis modify the role of the extensor muscles. Clin Biomech (Bristol, Avon), 2000, 15: 777-780. [Medline] [CrossRef]

15) Hoseinifar M, Ghiasi F, Akbari A: The relationship between lumbar and thoracic curves with body mass index and low back pain in students of Zahedan university of medical sciences. J Med Sci, 2007, 7: 984-990. [CrossRef]

16) Kamali N, Ahmadi MH, Kashami M, et al.: The effect of gender and obesity on lumbar lordosis. J Baboul Univ Med Sci. 2004, 6: 38-39.

17) Tüzün C, Yorulmaz I, Cindaş A, et al.: Low back pain and posture. Clin Rheumatol, 1999, 18: 308-312. [Medline] [CrossRef]

18) Song MY, Chung WS, Kim SS, et al.: Correlation between obesity and lumbar lordosis in obese pre-menupausal Korean females. J Korean Orient Med, 2004, 25: 43-50.

19) Ridola C, Palma A, Ridola G, et al.: Changes in the lumbosacral segment of the spine due to overweight in adults. Preliminary remarks. Ital J Anat Embryol, 1994, 99: 133-143. [Medline]

20) Tizabi AA, Mahdavinejad R, Azizi A, et al.: Correlation between height, weight, BMI with standing thoracic and lumbar curvature in growth ages. World J Sport Sci, 2012, 7: 54-56.

21) Purepong N, Boonyong S: Effects of McKenzie's exercise on pain and lumbar sagittal mobility in low back dysfunction syndrome patients. J Allied Health Sci, 2001, 2: 95-105.

22) Purepong N, Jitvimonrat A, Boonyong S, et al.: Effect of flexibility exercise on lumbar angle: a study among non-specific low back pain patients. J Bodyw Mov Ther, 2012, 16: 236-243. [Medline] [CrossRef] 
23) Weisell RC: Body mass index as an indicator of obesity. Asia Pac J Clin Nutr, 2002, 11: S681-S684. [CrossRef]

24) Ray L, Lipton RB, Zimmerman ME, et al.: Mechanisms of association between obesity and chronic pain in the elderly. Pain, 2011, 152: 53-59. [Medline] [CrossRef]

25) Tillotson KM, Burton AK: Noninvasive measurement of lumbar sagittal mobility. An assessment of the flexicurve technique. Spine, 1991, 16:
29-33. [Medline] [CrossRef]

26) Vismara L, Menegoni F, Zaina F, et al.: Effect of obesity and low back pain on spinal mobility: a cross sectional study in women. J Neuroeng Rehabil, 2010, 7: 3. [Medline] [CrossRef]

27) Christie HJ, Kumar S, Warren SA: Postural aberrations in low back pain. Arch Phys Med Rehabil, 1995, 76: 218-224. [Medline] [CrossRef] 